NASA-TM-100278

NASA Technical Memorandum 100278

\title{
Probabilistic Structural Analysis to Quantify Uncertainties Associated With Turbopump Blades
}

Vinod K. Nagpal and Robert Rubinstein

Sverdrup Technology, Inc.

Lewis Research Center

Cleveland, Ohio

and

Christos C. Chamis

Lewis Research Center

Cleveland, Ohio

February 1988

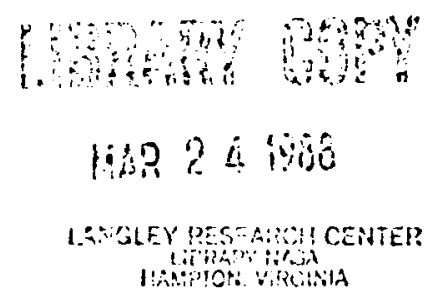

NASA 


\section{PROBABILISTIC STRUCTURAL ANALYSIS TO QUANTIFY UNCERTAINTIES \\ ASSOCIATED WITH TURBOPUMP BLADES \\ Vinod K. Nagpal, Robert Rubinstein \\ Sverdrup Technology, Inc. \\ Lewis Research Center \\ Cleveland, Ohio 44135}

and

Christos C. Chamis

National Aeronautics and Space Administration

Lewis Research Center

Cleveland, Ohio 44135

\section{SUMMARY}

A probabilistic study of turbopump blades has been in progress at NASA Lewis Research Center for over the last 3 years. The objective of this study is to identify the influencing variables and quantify the effects of uncertainties in these variables on the structural response of critical structural components. This paper reports the effects of uncertainties in two of the identified variables which are geometry and material properties. The quantified effects of the variables will provide a more reliable ground to evaluate the tolerance limits on the design. A methodology based on probabilistic approach has been developed to quantify the effects of the random uncertainties. The results of this study indicate that the uncertainties only in geometry have significant effects on the structural response.

\section{INTRODUCTION}

Geometry and material properties are generally considered deterministic when designing or analyzing structural components. Contrarily, in most cases, these have random variations known as uncertainties in geometry and material properties, and sometimes even in loading. These uncertainties often conservatively are accounted for in the design by a factor of safety. It is true that these uncertainties are usually small in magnitude, but they sometimes have a significant effect on the structural performance of critical components such as turbine blades. Therefore, for these types of components, it is very important to quantify their influence on the structural response.

The first step of this study was to develop a methodology to quantify the influence of these random uncertainties on the performance of structural components. The second step was to apply this methodology to quantify the effects of uncertainties in geometry, material properties, and loadings. The component selected for the study was the Space Shuttle Main Engine (SSME) turbopump blade (fig. 1). As a first phase of the study, variations associated with geometry and material properties have been investigated. Quantifying the influence of uncertainties in the loadings is underway and will be reported in the near future. 
Many studies have demonstrated that probabilistic analysis methods for components under random loading are more reliable than deterministic approaches. Probabilistic methods have been predominantly used in fatigue, fracture mechanics, and structural reliability analyses under random vibrations (refs. 1 to 5). Particularly in fatique, improvements in estimating fatigue life ranged up to several hundred percents in comparison to a widely used deterministic approach (ref. 6). Because of the potential, the application of probabilistic methods have been accepted in the other fields of engineering in recent years. These fields include input loading, finite elements, and metallurgy. A probabilistic approach to develop a composite loading for SSME components is currently underway at the Battelle laboratories (ref. 7), and has been discussed by Shinozuka and Lin (refs. 8 and 9). Other studies using probabilistic finite element methods have been briefly reviewed by DasGupta (ref. 10). A variational approach for developing the probabilistic finite elements is currently under development by Belytschko (ref. 11). The usefulness and importance of the probabilistic approach, especially for turbopump blades, has been summarized by Chamis (ref. 12).

The influence of the uncertainties in geometry and material properties in this study were quantified by computer simulations. The structural response was estimated under different levels of uncertainties using finite element methods. No real experiments were performed. Conducting experiments for studying the influence of three or more random variables with four or five levels and the Monte Carlo simulation technique is extremely complex and expensive, and in some cases, impossible with the state-of-the-art. Every time a variable or a level of variable is added to the study the number of experiments increase exponentially.

\section{ANALYSIS PROCEDURE}

The influence of random variations in geometry and material properties have been studied by modifying and using a NASA Lewis finite element code known as STAEBL (Structural Tailoring of Engine Blades). STAEBL modeled the aerofoil of the turbopump blade with 80 triangular shell elements consisting of 55 nodes. The blade dimensions are 1.25 by 1.00 by 0.25 in. A typical blade geometry is shown in figure 1 .

The influences of random variations both in geometry and material properties, were quantified in terms of variations in the structural response of the blade. The structural response of the blade was characterized in terms of three variables. These were the first three natural frequencies, the normal stress (root stress) at the fixed end (junction of the aerofoil and the platform) and lateral blade tip displacements. The first three natural frequencies were considered sufficient for the purpose of methodology development. However, the number of frequencies can be increased to any reasonable number by making a simple modification in the computer code.

Geometry uncertainties were simulated by randomly perturbing the nodal coordinates of the finite element mesh. All three geometrical coordinates ( $x$, $y, z$ ) of each node were perturbed using random numbers generated from a computer. The generated random numbers were added vectorially to the nodal coordinates after the numbers were multiplied by a constant. Different constants were used for perturbations in different directions. The constants were obtained such that the maximum magnitude of perturbation in any direction 
did not exceed 10 percent of the distance between two consecutive nodes in that direction. A sample of perturbed geometry is shown in figure 2.

Material property uncertainties were simulated by perturbing the components of material property matrix for each finite element. Since the blade was very thin and the property matrix is symmetrical, only six components, which correspond to in-plane load resistance needed to be perturbed. Other components of matrix were either zero or due to symmetry did not require perturbation. The maximum perturbation was once again limited to 10 percent of the original magnitudes of the properties. Ten percent maximum perturbation was justified by previous experience and a simplified spot experiment.

To determine the extent of variables of interactions, geometry and material properties were perturbed simultaneously. Insignificant variables, which otherwise would have unnecessarily made the study more complex, were eliminated by this procedure.

A factorial design, rather than a parametric approach, was selected to perform this study. This design is considered an organized and economical method to conduct experiments or simulations to study the influence of large number of variables. A large number of unnecessary tests or simulations can be eliminated by this design. This design helps identify insignificant variables, thereby reducing the computation cost and complexity of the study. Another advantage is that this design provides the option of widening the magnitude range of the variables by allowing the additional tests outside the preselected ranges. The design with added tests is called Central composite Design.

A factorial design and a Central Composite Design for three variables are illustrated in figures 3 and 4 . Solid circles on the corners, centers, and variable axes of the boxes in these figures represent test or simulation conditions. The limitation of the design is that the results, or the models developed using these results, are only applicable within the range covered by the design. A detail discussion of this method is given in reference 13 . In the parametric approach, one variable is varied at a time. The number of tests or simulations needed to perform such studies using parametric approach is enormous.

Simulated runs were made at each corner point of the $n$ dimensional box where $n$ stands for number of variables. For study on geometrical uncertainty, $n$ equaled 3 , for material property study, $n$ equaled 6 , and for interaction study, $\mathrm{n}$ equaled 6 . The order of the runs was randomized. Also, for each part of study the range of each variable was extended by using central composite design.

\section{MODEL AND PROBABILITY DISTRIBUTION}

Probabilistic models were developed for all response variables for each part of the study using regression analysis. Coefficients and their standard deviations for each of the study variables were estimated. Using standard deviations and t-tests, it was determined whether a given variable was significant or not. After all the models were developed, F-tests and $x^{2}$ (Chi) square tests were also used. These tests provided "goodness-of-fit" estimates of the models and a measure of randomness of the residuals. Models which satisfied this criteria were accepted. These models are of the form; 


$$
Y=\alpha_{0}+\alpha_{1} V_{1}+\alpha_{2} V_{2}+\alpha_{3} V_{3}+\cdots+\alpha_{n} V_{n}
$$

where $Y$ is a response variable, $\alpha_{0}, \ldots-\cdots, \alpha_{n}$ are the coefficients and $V_{1}$, - - - , $1 / n$ are the variables of the study. The residuals of the model were plotted and their auto correlations were plotted before a model was finally selected or rejected. A sample plot of residuals for one of the models is shown in figure 5 . This plot indicates that the residuals are randomly distributed. Proabability distributions for all response variables were developed for selected simulated runs by replicating them a large number of times. Every replication employed random numbers to establish perturbation values.

\section{RESULTS AND ANALYSIS}

A methodology to perform probabilistic structural analysis has been developed. It can be used to quantify the influence of random variations or uncertainties in the structural variables on the performance of a given component. The methodology was developed using computer simulations. These simulations could be used to reduce the high costs and complexity of extensive and unnecessary experimentation. These advantages are further underscored by the reduced time an engineer/scientist must expend to arrive at these results.

The results reported in this study, as mentioned before, are all computersimulated results. The magnitudes of coefficients $\alpha_{1}, \alpha_{2},-$ - $_{\text {. }}$, an for geometric variables, material property variables, and cross terms (interaction terms) are listed in tables I, II, and III, respectively. The significance test (t-test) of the coefficients in table I indicated that only variance of the geometry perturbations along the thickness is significant. The perturbations along other directions are insignificant and should be considered insignificant while setting the tolerances. The probable reason that these perturbations are insignificant is that they are relatively small in magnitude. Although F-tests showed that all the models are good fits, they are not the desired models since they include insignificant variables. A model using the significant variable alone was also developed (not shown here). This model predicted estimates close to the actual values and was found to be a good fit.

Probabilistic distributions of all the response variables were obtained based on 120 to 500 simulated replications. Figure 6 shows the probability distributions of first natural frequency as a result of geometry perturbations and similarly figure 7 shows the probability distributions of root stress. These distributions provide estimates of two items: (1) a range of variation of a response variable for any given random variation in the geometric variables, and (2) probability of occurrence of a response variable. This information is valuable for the designer in order to adjust the design tolerance limits. If the range does not include any critical value, the tolerances can be relaxed. An obvious advantage will be that the manufacturing cost will be reduced. These estimates can be further improved if the number of replications is increased.

Significance tests were performed on the coefficients of material property model (table II). These tests indicated that all the coefficients are statistically insignificant. This means that the uncertainties in material properties within 10 percent of their original magnitudes did not have any significant influence on the response variables. The variations of the response variables were truly random. Therefore, controlling the material property 
uncertainties would not necessarily improve the response. The distribution of all response variables corresponding to the variation in material properties were obtained. A sample plot of the variation in first natural frequency is shown in figure 8 . This distribution provides estimates of range and variations in the first natural frequency.

Significance tests were also performed on the coefficients (table III) of models developed to estimate the effects of interactions. These tests indicated that all the interaction effects are statistically insignificant. This means that response to simultaneous variation in geometry and in material properties are statistically independent.

The statistical analysis was used to eliminate any insignificant variables from the study. Since this study is continuing, these interim conclusions were used to reduce computer costs. Work is continuing in developing higher order models. These models include estimating variances of the response variables. Some interesting results have been obtained. These will be published in the near future.

\section{FUTURE WORK}

The future work includes determining the influence of random variations in temperature, pressure, and loadings. The loadings include random pulse loading, thermal loading, and random loading in the elastic and inelastic ranges.

\section{CONCLUSIONS}

1. A methodology has been developed to quantify the influence of random variations or uncertainties in the geometry, material properties, and loadings on the response variables. This methodology provides answers which may be used as a guideline to set the tolerance limits for design purposes.

2. Based on this study of the turbopump blade, it was found that random variations or uncertainties in geometry have statistically significant influence on the response variable. Therefore, tolerance limits should give due consideration to geometric variations along thickness.

3. Random variations or uncertainties in material properties have statistically insignificant effects on the response variables. Therefore, tolerance on material property variations need not be precise.

4. The methodology presented in this paper can be used for identifying the insignificant variables.

\section{REFERENCES}

1. Huang, T.C.; and Nagpal, V.K.: Probabilistic Factors, Experimental Design and Statistical and Variance Analyses for Fatigue Under Random Vibrations. Random Vibrations, T.C. Huang and P.D. Spanos, eds., ASME, 1984, pp. 51-68. 
2. Dover, W.D.: Fatigue Crack Growth in Tubular Welded Connections. Second International Conference on Behavior of Offshore Structures, Vol. 1, held at Imperial College, London, England, August 1979, pp. 507-522.

3. Yang, J.N.: Reliability Analys is of Aircraft Structures. Proceedings of the Symposium on Probabilistic Methods in Structural Engineering, M. Shinozuka and J.T.P. Yao, eds., American Society of Civil Engineers, New York, 1981, pp. 102-120.

4. Wirsching, P.H.: Fatigue Reliability Analysis in Offshore Structures. Proceedings of the Symposium on Probabilistic Methods in Structural Engineering, M. Shinozuka and J.T.P. Yao, eds., American Society of Civil Engineers, New York, 1981, pp. 295-307.

5. Kawamoto, J.; Sunder S.S.; and Connor, J.J.: An Assessment of Uncertainties in Fatigue Analyses of Steel Jacket Offshore Platform. Applied Ocean Research, vol. 4, no. 1, Jan. 1982, pp. 9-16.

6. Miner, M.A.: Cumulative Damage in Fatigue. J. Appl. Mech., vol. 12, no. 3, Sept. 1945, pp. 159-164.

7. Kurth, R.: Composite Loads Spectra For Select Space Propulsion Structural Components. Structural Integrity and Durability of Reusable Space Propulsion Systems, NASA CP-2381, 1985, pp. 77-83.

8. Shinozuka, M.; and Tan, R.: Probabilistic Load Combinations and Crossing Rate. Proceedings of the Symposium on Probabilistic Methods in Structural Engineering, M. Shinozuka and J.T.P. Yao, eds., American Society of Civil Engineers, New York, 1981, pp. 229-250.

9. Lin, Y.K.: Random Vibrations of Some Civil Structures. Proceedings of the Symposium on Probabilistic Methods in Structural Engineering. M. Shinozuka and J.T.P. Yao, eds., American Society of Civil Engineers, New York, 1981, pp. $210-228$.

10. DasGupta, G.: Literature Review on Probabilistic Structural Analysis and Stochastic Finite Element Methods. Probabilistic Structural Analysis Methods For Select Space Propulsion System Components, Southwest Research Institute, Annual Report, Mar. 1986.

11. Belytschko, T.; and Wing, K.L.: Probabilistic Finite Element Variational Theory. Structural Integrity and Durability of Reusable Space Propulsion Systems, NASA CP-2381, 1985, pp. 99-108.

12. Chamis, C.C.: Probabilistic Structural Analysis Methods for Critical SSME Propulsion Components. 3rd Space System Technology Conference, AIAA, 1986, pp. 133-144.

13. Box, G.E.P.; Hunter, W.G.; and Hunter, J.S.: Statistics for Experimenters: An Introduction to Design, Data Analysis, and Model Building. Wiley, 1978. 
TABLE I. - PROBABILISTIC MODELS - GEOMETRIC PERTURBATIONS

[Mode]: Dependent variab]e $=$ Constant + Coeff $* \mu_{1}+$ Coeff $* \mu_{2}$

+ Coeff $* \mu_{3}+$ Coeff $* \sigma_{4}+$ Coeff $* \sigma_{5}+$ Coeff $* \sigma_{6} . F$ tests

indicated that all models are good fits.]

\begin{tabular}{|l|r|r|r|r|r|r|r|}
\hline \multirow{2}{*}{$\begin{array}{l}\text { Dependent } \\
\text { variable }\end{array}$} & Constant & \multicolumn{7}{|c|}{ Coefficients of } \\
\cline { 3 - 8 } & & \multicolumn{1}{|c|}{$\mu_{1}$} & $\mu_{2}$ & \multicolumn{1}{c|}{$\mu_{3}$} & \multicolumn{1}{c|}{$\sigma_{4}$} & \multicolumn{1}{c|}{$\sigma_{5}$} & $\sigma_{6}$ \\
\hline First frequency & 6105 & -832 & -2915 & -687 & -8362 & -1897 & -9348 \\
Second frequency & 9475.1 & -1374 & -2961 & -408 & -11398 & -3869 & -9095 \\
Third frequency & 15792 & -9434 & 27592 & -7944 & -17663 & -4899 & -44147 \\
Root stress & 63323 & 49707 & 103320 & 4177 & 88960 & -48191 & 283960 \\
Tip displacement & 0.00196 & 0.0119 & 0.1287 & 0.0206 & 0.0132 & 0.0419 & 0.0067 \\
\hline
\end{tabular}

TABLE II. - PROBABILISTIC MODELS - MATERIAL PROPERTIES PERTURBATIONS

(DIFFERENT BLADE PROPERTIES)

[Mode1: Dependent variable $=P=$ Constant + Coeff $\left._{1} * C_{1}\right]+$ Coeff $_{2} * C_{12}$ + Coeff $_{3} * C_{13}+$ Coeff $_{4} * C_{22}+$ Coeff $_{5} * C_{23}+C_{\text {oeff }} \times C_{33} \cdot F^{2}$ tests indicated that the models are not good fits.]

\begin{tabular}{|c|c|c|c|c|c|c|c|}
\hline \multirow{2}{*}{$\begin{array}{l}\text { Dependent } \\
\text { variable } \\
q\end{array}$} & \multirow[t]{2}{*}{ Constant } & \multicolumn{6}{|c|}{ Coefficient of } \\
\hline & & $c_{11}$ & $c_{12}$ & $c_{13}$ & $c_{22}$ & $\mathrm{C}_{23}$ & $c_{33}$ \\
\hline $\begin{array}{l}\text { First frequency } \\
\text { Second frequency } \\
\text { Third frequency } \\
\text { Root stress } \\
\text { Tip displacement } 1 \\
\text { Tip displacement } 2 \\
\text { Tip displacement } 3\end{array}$ & $\begin{array}{r}4769.7 \\
5501.9 \\
9653 \\
97673 \\
0.0121 \\
0.0113 \\
0.0012\end{array}$ & $\begin{array}{r}-239.1 \\
-342.6 \\
-788.6 \\
498 \\
0.0031 \\
0.0029 \\
0.0023\end{array}$ & $\begin{array}{r}-64.1 \\
-25.5 \\
-0.8 \\
-4001 \\
0.0004 \\
-0.0006 \\
-0.0004\end{array}$ & $\begin{array}{l}-55.1 \\
-96.7 \\
-61.5 \\
-1336 \\
0.0001 \\
0.0008 \\
0.0001\end{array}$ & $\begin{array}{r}-69 \\
-250.7 \\
-909.6 \\
-9962 \\
0.0011 \\
0.0008 \\
0.0003\end{array}$ & $\begin{array}{r}63.2 \\
110.4 \\
185.7 \\
-12154 \\
0.0005 \\
0.0004 \\
0.0007\end{array}$ & $\begin{array}{r}47.1 \\
52.2 \\
-63.6 \\
16701 \\
0.00133 \\
0.00133 \\
0.0010\end{array}$ \\
\hline
\end{tabular}

TABLE III. - PROBABILISTIC MODELS - COMBINED GEOMETRIC AND MATERIAL PERTURBATIONS TOGETHER

[Model: Dependent variable $P=$ Constant + Coeff ${ }^{*} \sigma_{1}+---+$ Coeff $_{6}{ }^{*} \sigma_{33}$ +-- Coeff $_{21} * \sigma_{31} * \mathrm{C}_{33}$. Coefficients of all cross terms (not shown) and material property were insignificant. Tip displacements coefficients to be divided by 1000.]

\begin{tabular}{|l|r|r|r|r|r|r|r|}
\hline \multirow{2}{*}{$\begin{array}{c}\text { Dependent } \\
\text { variable }\end{array}$} & Constant & \multicolumn{6}{|c|}{ Coefficients of } \\
\cline { 3 - 8 } & & \multicolumn{1}{|c|}{$\sigma_{1}$} & \multicolumn{1}{|c|}{$\sigma_{2}$} & \multicolumn{1}{c|}{$\sigma_{3}$} & \multicolumn{1}{c|}{$c_{11}$} & \multicolumn{1}{c|}{$c_{22}$} & $c_{33}$ \\
\hline First frequency & 6185.7 & -336.2 & 320.6 & -1588.1 & -60.8 & -15.37 & -44.9 \\
Second frequency & 8901.5 & 146 & -299 & -524 & -40.1 & -68.4 & -70.3 \\
Third frequency & 15267 & 17.4 & -2307 & 12324 & -79.7 & -294 & -106 \\
Root stress & 85450 & -25410 & -39280 & -80 & -2080 & -3260 & -1920 \\
Tip displacement 1 & -1.7 & -0.10 & 3.3 & -3 & -0.1 & 0.1 & -0.1 \\
Tip displacement 2 & 2.0 & 1.5 & 2.0 & 1.2 & -0.1 & -0.1 & 0.0 \\
Tip displacement 3 & -3.1 & -3 & -2.6 & 0.70 & -0.2 & 0.1 & -0.2 \\
\hline
\end{tabular}




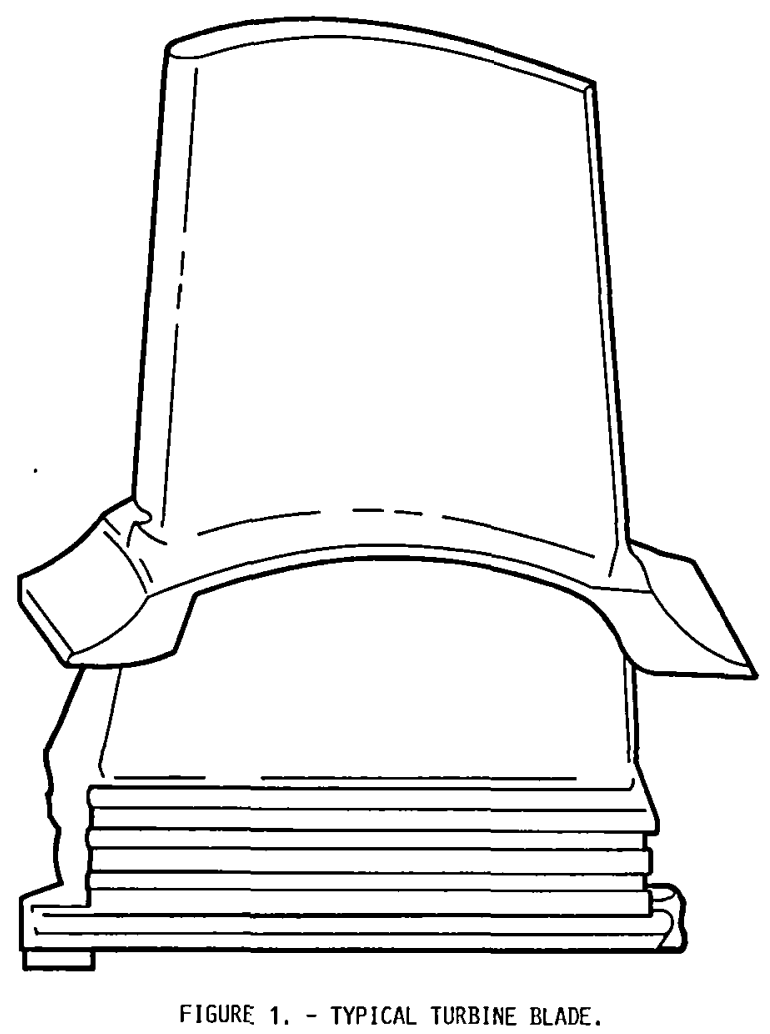




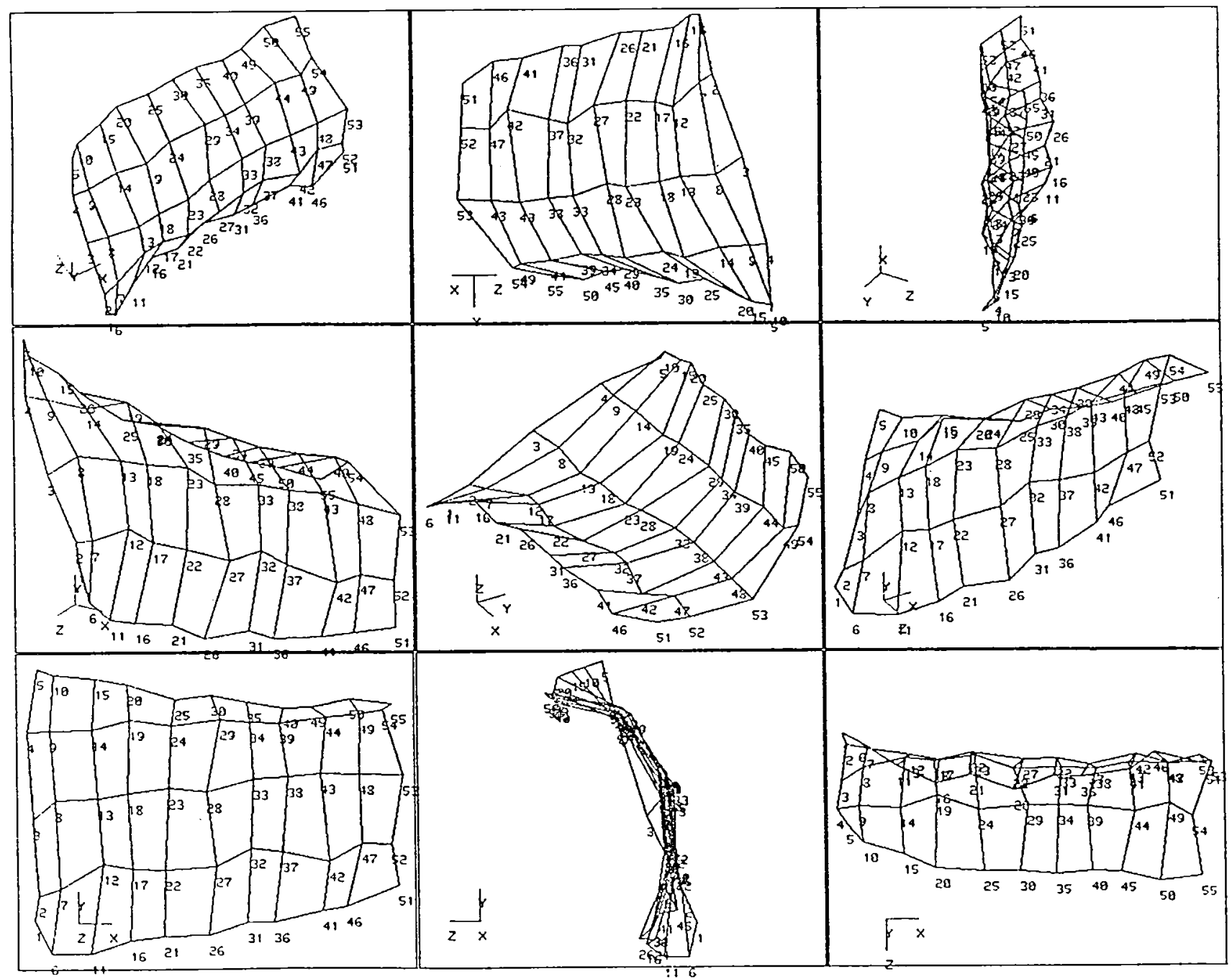

FIGURE 2. - PERTURBED BLADE GEOMETRY. 


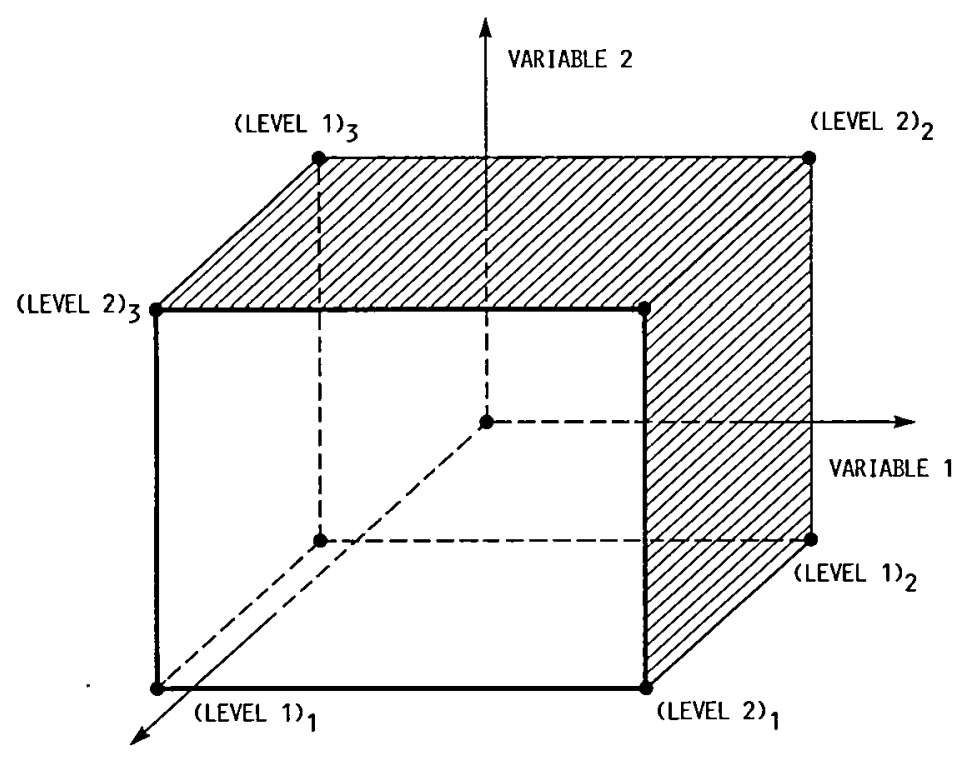

VARIABLE 3

FIGURE 3.- FACTORIAL DESIGN FOR THREE VARIABLES.

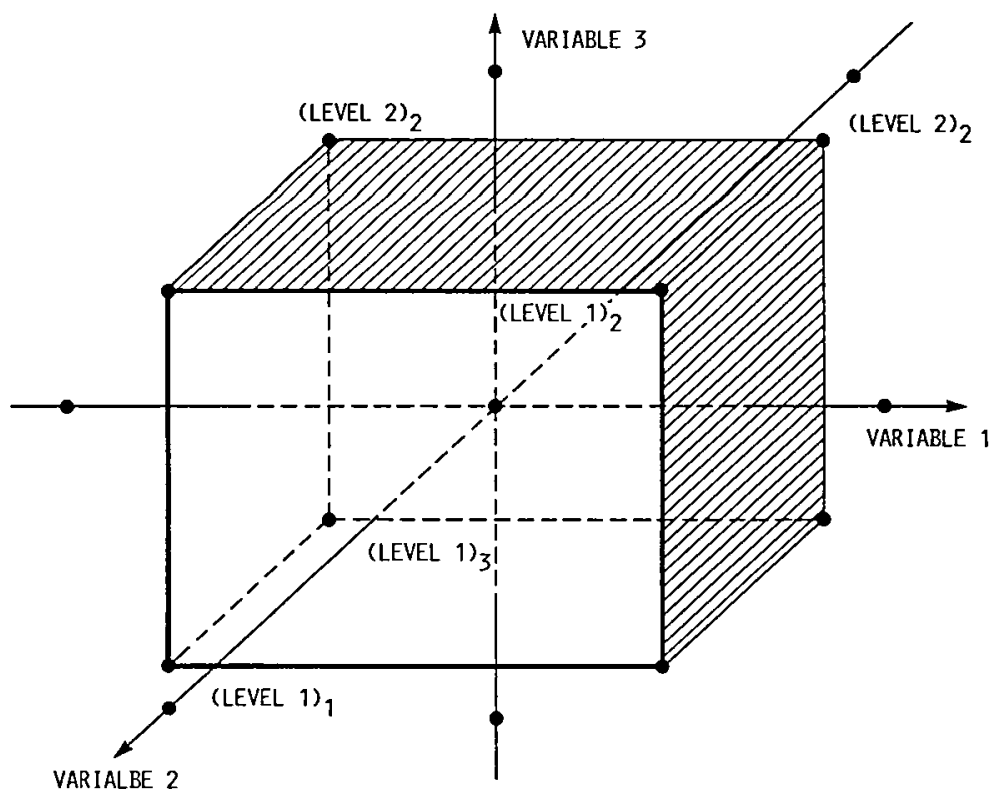

FIGURE 4. - CENTRAL COMPOSITE DESIGN FOR THREE VARIABLES. 

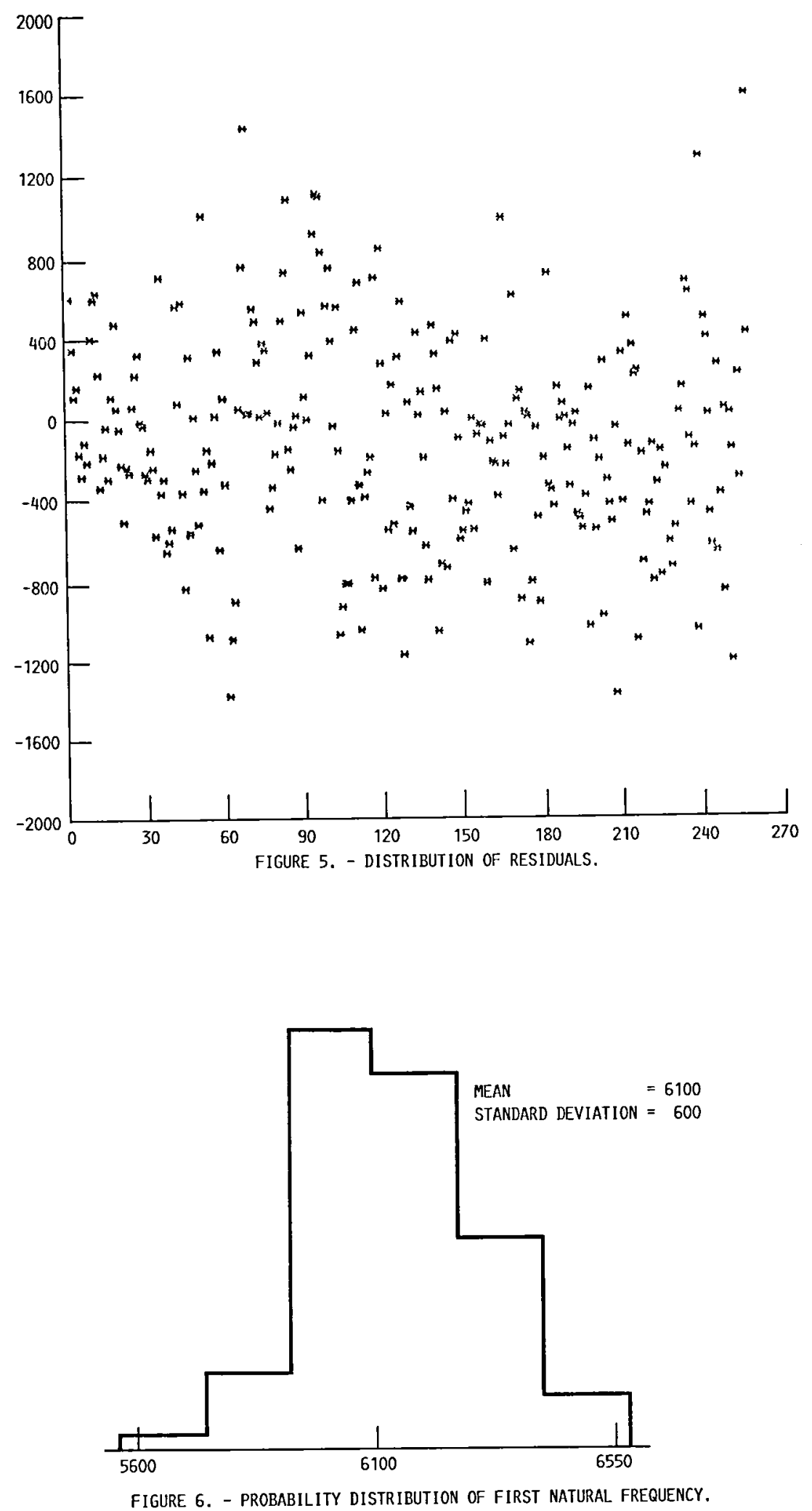


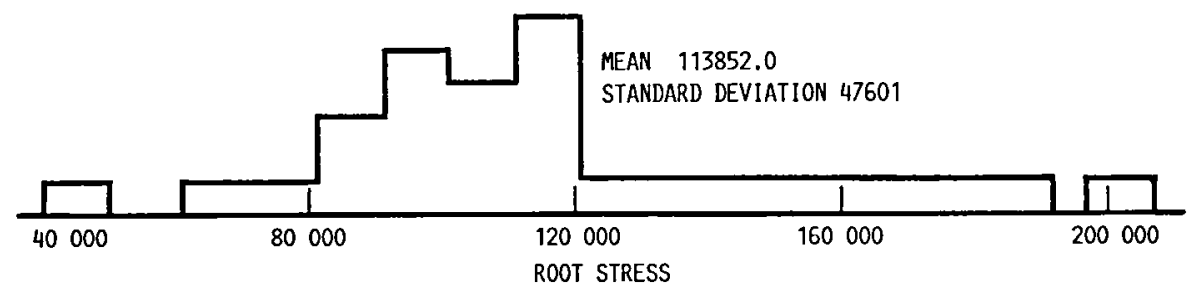

FIGURE 7. - PROBABILITY DISTRIBUTION OF ROOT STRESS.

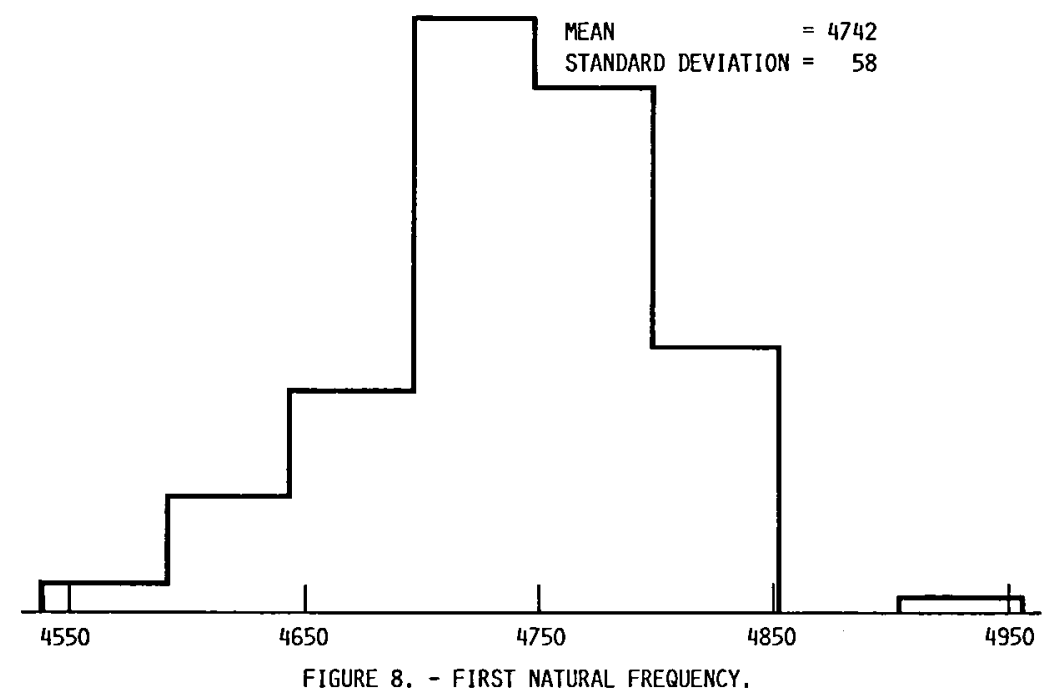




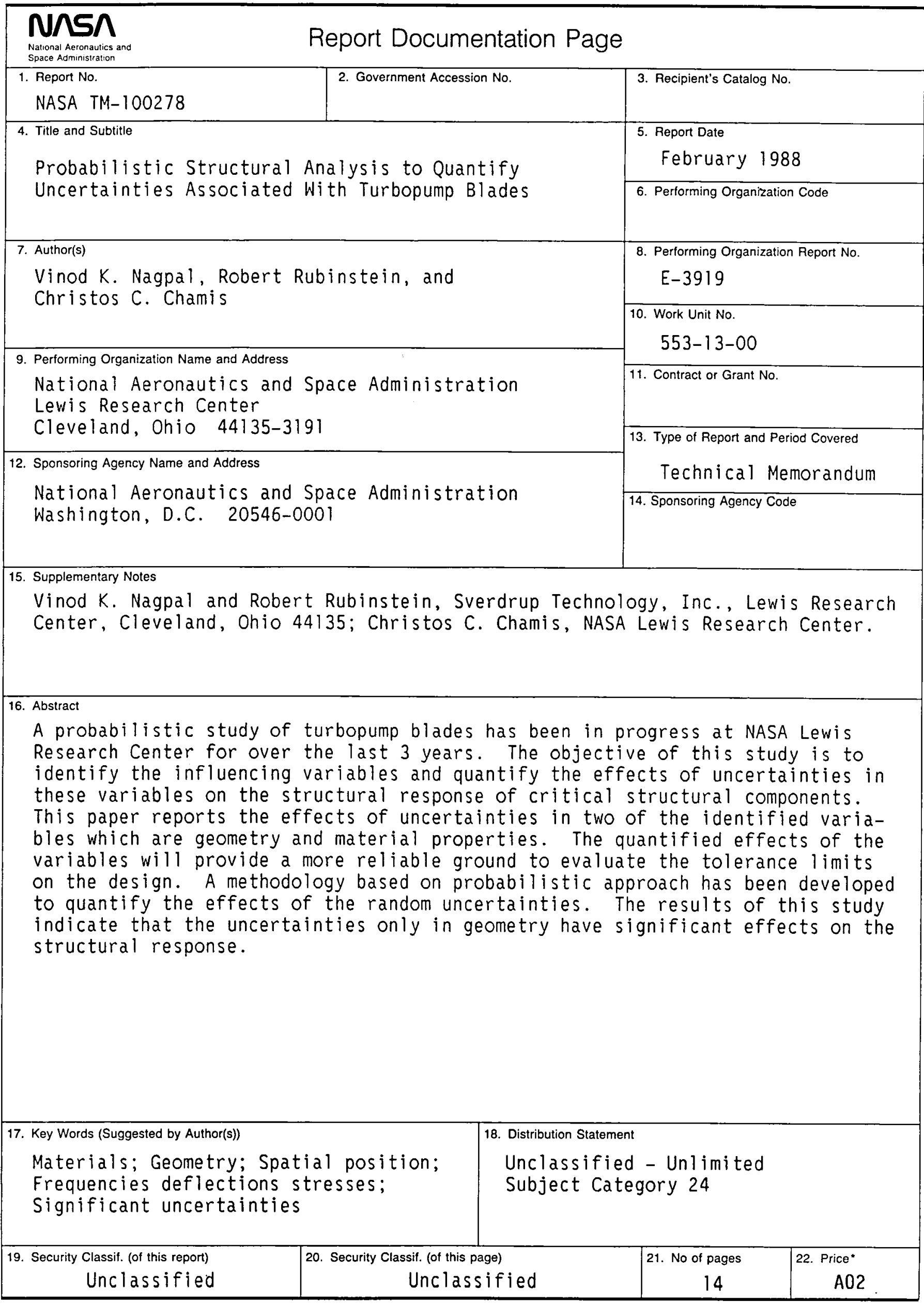


National Aeronautics and Space Administration

SECOND CLASS MAIL

Lewis Research Center

Cleveland. Ohio 44135

Official Business

Penalty for Pitvate Use $\$ 300$

\section{ADDRESS CORRECTION REQUESTED}

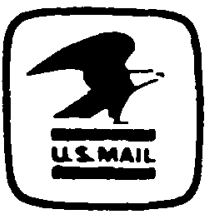

Postage and Fees Paid National Aeronautics and Space Administration NASA-451 